\title{
Strengths and Limitations of Using the Polypill in Cardiovascular Prevention
}

\author{
Ambuj Roy ${ }^{1}$ - Nitish Naik ${ }^{1}$ K. Srinath Reddy ${ }^{2}$ \\ Published online: 19 April 2017 \\ (C) The Author(s) 2017. This article is an open access publication
}

\begin{abstract}
Purpose of Review Polypill and its role in cardiovascular disease (CVD) prevention has been extensively discussed and debated since the inception of the concept in 2003. This article reviews the subsequent accumulated research in this area. Recent Findings Several short and intermediate to long-term studies with different brands of polypills have analysed the impact of polypill in phase II and III trials. The strengths of polypill that have emerged include better adherence, equivalent or better risk factor control and quality of life among polypill users as compared to usual care. The lurking limitations include difficulty with dose adjustment to targets, fear of mass medicalisation and low acceptability among physicians. Summary The current literature supports polypill use in reducing blood pressure and cholesterol levels for CVD prevention with improvement in adherence to medication. However, the long-term outcome of polypill on CVD events and mortality are unavailable and are currently being studied in clinical trials.
\end{abstract}

Keywords Polypill · Fixed dose combination · Cardiovascular diseases $\cdot$ Adherence $\cdot$ Secondary prevention . Primary prevention

This article is part of the Topical Collection on Lipid Abnormalities and Cardiovascular Prevention

K. Srinath Reddy

ksrinath.reddy@phfi.org

1 President, Public Health Foundation of India, New Delhi, India

2 Public Health Foundation of India, Delhi National Capital Region, Plot No. 47, Sector 44, Institutional Area, Gurugram 122002, India

\section{Introduction}

The concept of polypill or a fixed drug combination (FDC) was proposed, to reduce cardiovascular burden, rather dramatically in a much cited paper by Wald and Law in the year 2003 [1]. They proposed that this polypill comprising of six drugs (aspirin, statin, beta-blocker, angiotensin converting enzyme (ACE) inhibitor, diuretic and folic acid) could reduce burden of cardiovascular disease (CVD) by $80 \%$ when taken by all above the age of 55 years and those with CVD. The concept was based on research accumulated over years on the benefit of blood pressure lowering, cholesterol lowering and antiplatelet drugs in reducing CVD morbidity and mortality. Over the last decade or so the story of the polypill has progressed with both successes and disappointments [2•]. This review discusses the potential role of polypharmacy, the current state of research, strengths and limitations and the future directions that we foresee for the polypill.

\section{Importance of Polypharmacy in CVD Prevention}

CVD is the leading cause of mortality worldwide [3]. This is true of both the developed world and most of the developing countries. While CVD burden is declining in the developed countries, it is on the rise in developing countries with $80 \%$ of the burden projected to be in the lower and middle income countries (LMIC) by 2020 [4].

All current guidelines recommend aspirin and high dose statins for patients with established cardiovascular disease $[5,6]$. In addition most patients with CVD are advised beta blockers and ACE inhibitors as class I or IIA indication unless specifically contraindicated [5]. Modelling and nested case control studies have shown that this combination 
pharmacotherapy leads to a $75 \%$ reduction in mortality in patients with established CAD [7].

In patients without CVD, the strength of evidence for polypharmacy is not well established. While the benefits of management of individual risks like hypertension, dyslipidemia are well documented general use of aspirin, and statins remains controversial. Aspirin trials for primary prevention reduce non-fatal MI but have little impact on mortality, while consistently causing increase in risk of bleeding [8]. Similarly, the utility/efficacy of statin for primary prevention is not well established. Two large primary prevention trials did show benefit of use of rosuvastatin in reducing cardiovascular outcomes in individuals without CVD [9, 10]. However, they used a biomarker or clinical risk identifier to include at risk individuals to administer statin. Similarly, appropriate risk stratification strategy to identify high risk individuals for primary prevention with polypill needs to be tested before adopting it. This could be based on clinical scores [10] or novel investigations like calcium score, which has been claimed by authors in a modelling paper, to substantially bring down the number to treat (NNT) [11] as compared to basing it only on age as proposed by Wald and Law.

\section{Summary of Current Research}

The last decade has witnessed development of multiple polypills, with varying constituents, which have been tested in different trials. The polypills considered here for CVD prevention are those with at least one anti-hypertensive in addition to aspirin and statin. A list of these polypills studied or marketed is documented in Table 1.
These polypills have been studied in numerous research trials in comparison to placebo or usual care. These clinical trials have measured adherence rates, adverse events and risk factor control. None of these trials have enough power to test the impact of polypill on clinical outcomes. These are summarised in Table 2, and the different aspects of the trial are discussed below.

\section{Strengths}

\section{Adherence}

One of the formidable challenges in management of CVD is the requirement of adherence to medications over a long duration, sometimes life-long, in individuals who may be asymptomatic and thus the immediate benefits of therapy may not be perceived by them. The polypill is conceptualised to reduce pill burden and thus improve adherence. This was confirmed both in the short-term and intermediate to longterm studies done so far. Two short-term studies of 12 weeks comparing polypill to placebo revealed high adherence rates to polypill which was equivalent to placebo suggesting that adherence, at least in the short term, seems related to the pill count and not the constituents of the polypill [13, 14]. The three intermediate to long term studies of over 12 months: UMPIRE Trial [18], Kanyini GAP [19] and IMPACT [12] clearly demonstrated higher adherence in the polypill arm. A meta-analysis of four studies in patients with CVD or at highrisk for CVD demonstrated $44 \%$ higher adherence rates among polypill users as compared to usual care [22•] (Fig. 1). The individual participant data analyses from

Table 1 List of currently available polypills for research and clinical use

\begin{tabular}{|c|c|c|}
\hline Brand name & Constituents & Manufacturer \\
\hline Red Heart Pill ${ }^{\mathrm{TM}} 1$ & Aspirin (75 mg), atenolol (50 mg), lisinopril (10 mg), simvastatin (40 mg) & Dr. Reddy’s Laboratories,India \\
\hline Red Heart Pill ${ }^{\mathrm{TM}} 2$ & $\begin{array}{l}\text { Aspirin (75 mg), hydrochlorothiazide (12.5 mg), Lisinopril (10 mg), simvastatin } \\
\quad(40 \mathrm{mg})\end{array}$ & Dr. Reddy's Laboratories, India \\
\hline Trinomia $^{\circledR} /$ Sincronium $^{\circledR a}$ & Aspirin $(100 \mathrm{mg})$, ramipril $(2.5,5$ or $10 \mathrm{mg})$, atorvastatin $(20 \mathrm{mg})$ & Ferrer Internacional, Spain \\
\hline Trinomia $^{\circledR}$ & Aspirin $(100 \mathrm{mg})$, ramipril $(2.5,5$ or $10 \mathrm{mg})$, simvastatin $(40 \mathrm{mg})$ & Ferrer Internacional, Spain \\
\hline Polycap $^{\circledR}$ & $\begin{array}{l}\text { Atenolol (50 mg), hydrochlorothiazide }(12.5 \mathrm{mg}) \text {, ramipril }(5 \mathrm{mg}), \text { simvastatin } \\
\quad(20 \mathrm{mg}), \text { optional aspirin }(100 \mathrm{mg})\end{array}$ & Cadila Pharmaceuticals Ltd., India \\
\hline Starpill $^{\circledR}$ & Aspirin $(75 \mathrm{mg})$, losartan potassium $(50 \mathrm{mg})$, atenolol $(50 \mathrm{mg})$, atorvastatin $(10 \mathrm{mg})$ & Cipla, India \\
\hline Polypill $^{\mathrm{b}}$ & $\begin{array}{l}\text { Amlodipine }(2.5 \mathrm{mg}), \text { losartan }(25 \mathrm{mg}) \text {, hydrochlorothiazide }(12.5 \mathrm{mg}) \text {, simvastatin } \\
\quad(40 \mathrm{mg})\end{array}$ & Cipla, India \\
\hline PolyIran & $\begin{array}{l}\text { Aspirin }(81 \mathrm{mg}) \text {, enalapril }(5 \mathrm{mg}) \text {; or valsartan }(40 \mathrm{mg}), \text { hydrochlorothiazide }(12.5 \mathrm{mg}) \text {, } \\
\text { atorvastatin }(20 \mathrm{mg})\end{array}$ & $\begin{array}{l}\text { Alborz Darou Pharmaceutical } \\
\text { Company, Iran }\end{array}$ \\
\hline Ramitorva $^{\circledR}$ & Aspirin (75 mg), ramipril (5 mg), atorvastatin (10 mg) & Zydus Cadila, India \\
\hline
\end{tabular}




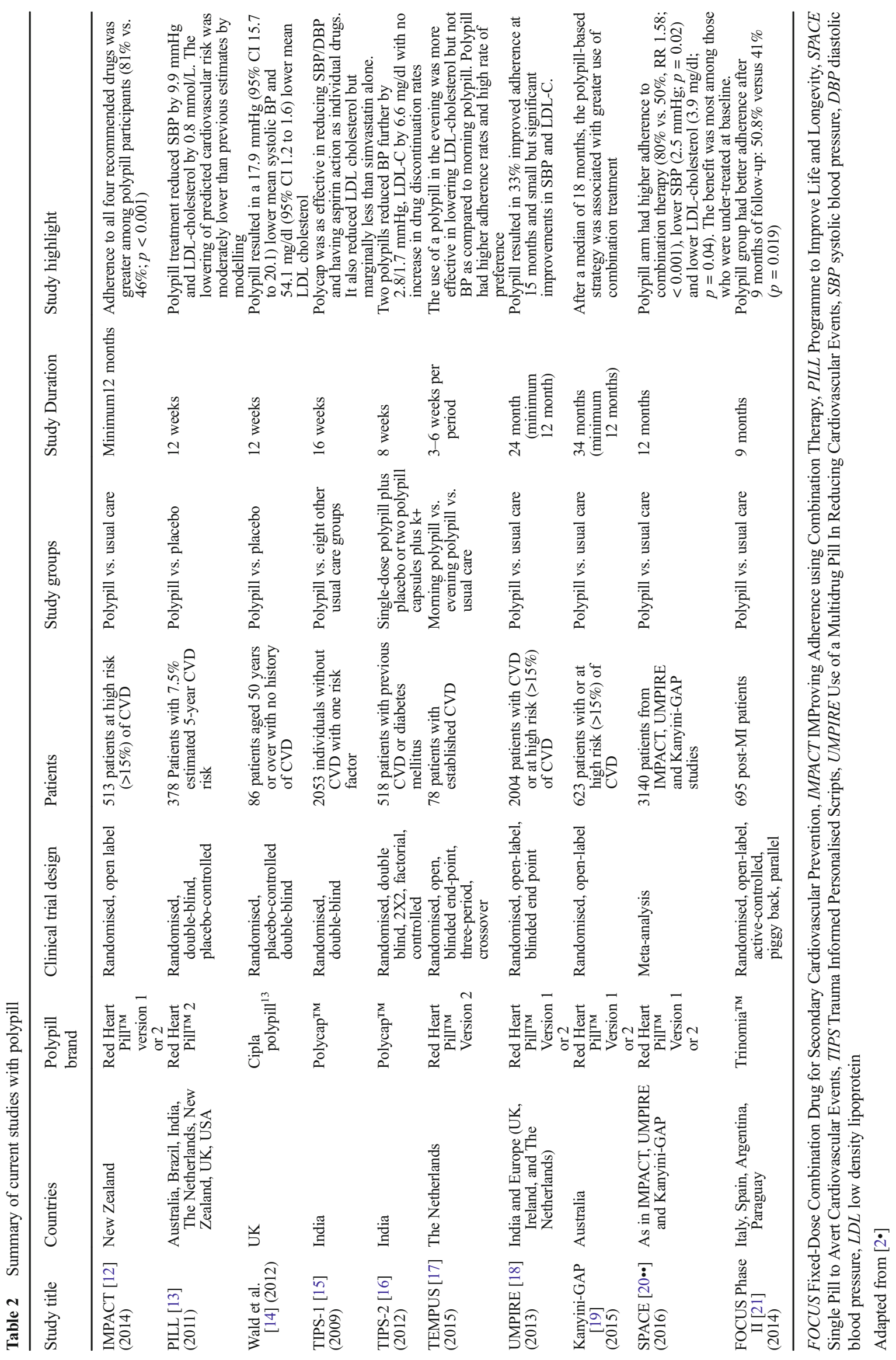


SPACE suggested that participants with low adherence at baseline had the highest improvement in adherence $(17 \%$ at baseline to $74 \%$ at trial end (relative risk $[\mathrm{RR}]=4.46[95 \% \mathrm{CI}$ : 3.72 to 5.36$]$ ), compared with participants who were already adherent at baseline ( 86 to $90 \%$; RR $=1.04[95 \% \mathrm{CI} ; 1.01$ to 1.07] [18]. Interestingly, the individuals without clinical CVD had a better risk ratio of adherence on polypill than usual care (2.12 vs. $1.4, p<0.001$ ) as compared to those with CVD in the SPACE study [20••]. The adherence rates also seem to be better with polypill with time as seen in the FOCUS trial [21]. The adherence rates in the usual care and polypill arm at 1 month being 54.8 and 59\%, respectively, with the difference increasing to 55.7 and $65.7 \%$, respectively, at 9 months. Thus from available data, it seems that the polypill improves adherence rates, more so in otherwise poorly compliant groups like those with poor baseline compliance, high risk cases on primary prevention and in subjects on long term therapy.

\section{Quality of Life}

The UMPIRE study showed that EQ-5D visual analog scale score was significantly higher in the polypill group $(2.43 ; 95 \%$ CI, $0.87-3.99 ; p=.002$ ) as compared to the usual care group indicating better patient perceived health on polypill [18]. However, the same test was not different in Kanyini-GAP study which could be due to the small sample size of this study [19]. Similarly, the third study with the Red Heart Pill, the IMPACT trial, did not reveal any difference in the QOL between groups but it did reveal that the polypill patients found their medication regime 'very easy' (53\% of polypill patients compared to $46 \%$ of usual therapy patients) [12]. This was also supported in the short-term Red Heart Pill study, where the polypill was preferred over usual care in $92 \%$ of patients in the TEMPUS trial [17].

\section{Cardiovascular Risk Factor Control}

Polypill combines multiple drugs within one tablet/capsule. While it is one thing to know the right pharmacological agents for primary and secondary prevention of CVD, it is important to be sure of the physico-chemical compatibilities of these agents within a combination pill. It is very important to conserve the biopharmaceutical and pharmacokinetic properties of every one of its components to have the desired pharmacodynamic effects needed for control of the targeted risk factor. In this context again there have been several studies both short-term phase II studies and clinical trials in real world settings. The meticulously designed TIPS-1 study was a phase II study to assess the effect of five drug polypill (Aspirin $100 \mathrm{mg}$, simvastatin $20 \mathrm{mg}$, ramipril $5 \mathrm{mg}$, hydrochlorthiazide $12.5 \mathrm{mg}$ and atenolol $50 \mathrm{mg}$ ) against eight groups comprising of aspirin alone, simvastatin alone, hydrochlorthiazide alone, three combinations of the two blood-pressure-lowering drugs, three blood-pressure-lowering drugs alone or three blood-pressure-lowering drugs plus aspirin [15]. The study revealed that at the end of 12 weeks, the blood pressure effect and the change in11-dehydrothromboxane B2, a surrogate for aspirin effect, were similar in polypill and other groups. The blood pressure lowering effect increased as the number of drugs increased being 2.2/1.3 mm $\mathrm{Hg}$ with one drug, 4.7/3.6 mmHg with two drugs and 6.3/4.5 $\mathrm{mmHg}$ with three drugs and $7.4 / 5.5 \mathrm{mmHg}$ with the polypill. The reduction in 11-dehydrothromboxane B2 were similar with the polypill (283.1 ng/mmol creatinine, 95\% CI 229·1-337·0) compared with the three blood-pressure-lowering drugs plus aspirin (350.0 ng/mmol creatinine, 294.6-404.0), and aspirin alone (348.8 ng/mmol creatinine, 277.6-419.9). However, the reduction in LDL cholesterol was lower with polypill; $0.70 \mathrm{mmol} / \mathrm{L}$ (95\% CI $0.62-0.78)$ vs. $0.83 \mathrm{mmol} / \mathrm{L}(0.72-0.93 ; p=0.04)$ seen with simvastatin alone; with both reductions being greater than for groups without simvastatin $(p<0.0001)$. The drug discontinuity rate of polypill was similar to that of other
Fig. 1 Percentage of adherent patients to the polypill and the comparator group in the various trials and the overall group. The relative risk and the $95 \%$ confidence interval of each comparison is mentioned above the bars [22•]

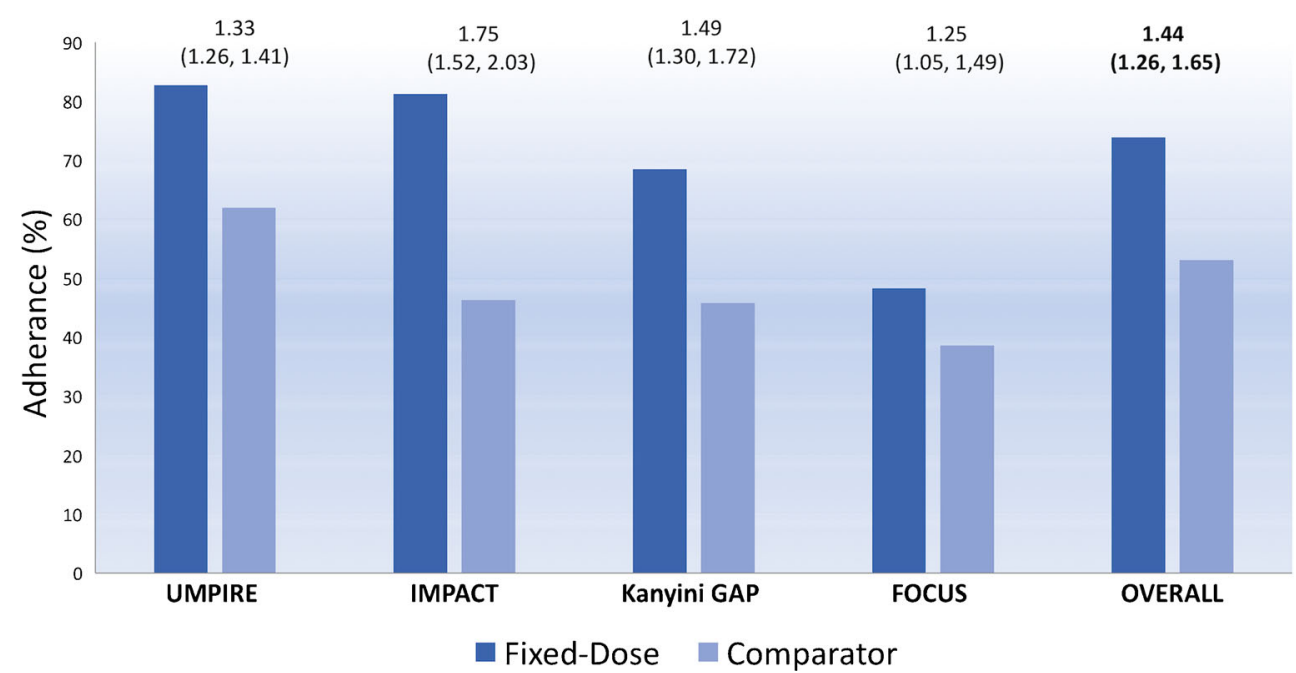


treatments, with no evidence of increasing intolerance with increasing number of active components in one pill [15].

Another randomised double-blind placebo-controlled crossover trial conducted by Wald et al. revealed higher blood pressure reduction and LDL cholesterol reduction which was closer to the predicted changes suggested in the early papers on polypill. This polypill comprised of amlodipine $2.5 \mathrm{mg}$, losartan $25 \mathrm{mg}$, hydrochlorothiazide $25 \mathrm{mg}$ and simvastatin $40 \mathrm{mg}$ and led to a reduction in systolic blood pressure of $17.9 \mathrm{mmHg}$ (95\% CI, 15.7-20.1); diastolic blood pressure of $9.8 \mathrm{mmHg}(95 \% \mathrm{CI}, 8.1-11.5)$ and LDL cholesterol of $54.1 \mathrm{mg} / \mathrm{dl}(95 \% \mathrm{CI}, 46.4 \mathrm{mg} / \mathrm{dl}-61.9 \mathrm{mg} / \mathrm{dl})$ as compared to placebo. The larger effect was probably due to choice and dose of anti-hypertensives, higher dose of simvastatin and cross-over design of the trial [14].

Early polypill trials in clinical settings comparing polypill to usual care like IMPACT [12], TEMPUS [17] and KanyiniGAP [19] did not observe any significant difference between the two groups in terms of BP and LDL cholesterol reduction despite reduced pill counts and improvement in adherence. However, most of these were small studies without sufficient statistical power to detect this benefit. The larger UMPIRE Trial demonstrated better blood pressure and cholesterol lowering throughout the study with end of study SBP and LDL$\mathrm{C}$ being $2.6 \mathrm{mmHg}$ and $4.2 \mathrm{mg} / \mathrm{dl}$, respectively, lower in the polypill arm [18]. These findings were corroborated by SPACE meta-analysis which revealed $2.5 \mathrm{mmHg}$ lower SBP and $3.5 \mathrm{mg} / \mathrm{dl}$ lower LDL-cholesterol in polypill arm [20••].

Thus, the polypill seems to be working better than usual care for risk factor control. Further refinement in the choice of anti-hypertensives and use of more potent statins in the future iterations would lead to even better results.

\section{Limitations}

\section{Titration of Doses}

Clinicians by training are taught to titrate dosages to 'treat to target' various risk factors. The key worry for most practitioners has been the inconvenience of dose adjustments with a polypill. The lack of ability to fine tune one component of the polypill if the therapeutic goals are not reached is a constant concern. However, the more recent guidelines have shifted to risk-based treatment for lipids irrespective of baseline cholesterol levels [23], and others have advocated the same for blood pressure [24]. This approach was tested for intermediate risk individuals without CVD in the HOPE-3 trial. The study included men above 55 years and women above 65 years with one additional cardiovascular risk factor. In a $2 \times 2$ factorial design individuals received rosuvastatin $10 \mathrm{mg} /$ day or placebo and fixed combination of candesartan
(16 mg per day) and hydrochlorothiazide (12.5 mg per day) or placebo. The trial demonstrated that individuals on dual therapy versus those on dual placebo had a $29 \%$ reduction (hazard ratio, $0.71 ; 95 \%$ confidence interval $[\mathrm{CI}], 0.56$ to 0.90 ; $p=0.005)$ in death from cardiovascular causes, non-fatal MI and non-fatal stroke. While the lipid lowering arm had $24 \%$ reduction (hazard ratio, $0.76 ; 95 \%$ confidence interval [CI], 0.64 to $0.91 ; p=0.002$ ) in the combined end point, the benefit in the blood pressure lowering arm was restricted to the top tertile with SBP above $143.5 \mathrm{mmHg}$ [25].

\section{Impact of Drug Intolerance}

The other concern with polypill has been that a side-effect of any one of the components can lead to discontinuation of all drugs. A Cochrane review revealed that discontinuation rates were $26 \%$ (95\% CI 1.02 to 1.55 ) higher in participants who were randomised to polypill [26] but comparator groups included participants receiving usual care and placebo. However, the long-term studies showing better risk factor control suggests that this increased discontinuation was offset by other advantages of polypill including better adherence.

\section{Low Acceptability among Physicians}

The buzz over polypill has now been around for several years. The studies with polypill have also been published, and in some countries like India it has been available in store; however, its use has not picked up. Polypills with more than two drugs have not picked up commercially, and the reasons for this need to be explored.

\section{Mass Medicalisation}

The other concern of polypill, since the first paper by Wald and Law on treating everyone above 50 years of age, was the mass medicalisation of the population. This would lead to rapid escalation in numbers qualifying to receive polypill. Another feared fallout of this approach is the poor compliance and non-adherence to life-style advice among polypill users. However, this is not borne out in the available clinical trials. In the UMPIRE Trial, the lifestyle changes were similar in the polypill group and the usual care group and showed improvement from baseline [18].

\section{Future Directions}

\section{Research}

The polypill has been an area of active research over the last decade as was discussed above. However, none of the studies performed so far were powered to detect the impact of polypill 
on cardiovascular events and mortality. The meta-analysis by SPACE collaborators revealed similar fatal and non-fatal cardiovascular outcomes during follow-up (5.9\% in polypill and $4.8 \%$ usual care arm, $p=0.18$ ). The all cause (1.6 vs. $1.8 \%$, $p=0.59)$ and cardiovascular mortality ( 1.1 vs. $0.8 \%, p=0.27)$ in the polypill and usual care arm, respectively, were also similar [20••]. Ongoing studies with larger patient population and longer follow-up like TIPS-3 [27], SECURE trial [28] and PolyIran trial [29] may be able to address this question and tease out the difference between these two approaches in the future. Importantly, the TIPS-3 trial is a purely primary prevention trial in medium to high risk individuals and thus will help understand the role of polypill in subjects without CVD. The study employs a $2 \times 2 \times 2$ factorial design testing whether polypill compared to placebo leads to prevention of cardiovascular death, stroke and $\mathrm{MI}$ in male participants aged over 55 years and female participants over 60 years and INTERHEAT risk score above 10 . The study would recruit 5000 subjects from ten different countries and follow up for about 5 years [27]. The SECURE trial on the other hand is a secondary prevention trial and will assess the potential of the polypill to prevent major cardiovascular events in 3206 elderly patients (aged $>65$ years) with recent MI, stroke or coronary revascularisation over a minimum period of 2 years [28]. The third large trial is the PolyIran trial being conducted exclusively in a developing country to assess the role of polypill in primary and secondary prevention. The study is expected to enrol 7000 participants over 50 years of age and follow them up over 5 years to document time elapsed before the first cardiovascular event [29].

The polypill, especially in primary prevention, also needs to be tested against a multi-component life-style intervention (Poly-lifestyle) like regular physical activity, healthy diet and optimum body weight to see their respective roles in preventing cardiovascular events. While the two approaches may not be mutually exclusive, it may be worthwhile testing the benefits of the two interventions in isolation and combination.

\section{Customisation of the Polypill}

The lack of enthusiasm after the initial hype for the prescription of the polypill even in countries where it is widely available, like India, could be due to lack of customisation of the CVD drugs for individual patients. A common polypill for all CVD prevention subsets is probably viewed as a shotgun approach by practitioners. There may thus be a need for customisation of the polypill into broad categories like those for CHD, stroke and high risk primary prevention. The polypill for secondary prevention among stroke patients has little basis for beta-blocker as one of the constituents. The polypill in this case should have aspirin, statin with diuretic or ACE inhibitors or both depending on the baseline blood pressure level [30]. The polypill for CAD could include aspirin, high dose potent statin, ACE inhibitors and beta-blockers. The polypill should be customised for high risk primary prevention based on baseline blood pressure levels in the light of the HOPE-3 blood pressure lowering trial, which showed benefit of blood pressure reduction only in the individuals in the highest tertile with high blood pressure [25]. Similarly, in these patients polypill with and without aspirin should be available to guide therapy based on individual risk of patients. In summary, a choice of four to six polypills instead of one, for different subsets of patients, may improve uptake of polypill prescription among physicians.

\section{Incorporation in the Health System}

World Health Organisation has outlined nine targets for reducing premature mortality from non-communicable diseases by $25 \%$ by 2025 . Two of these directly relate to pharmacotherapy in (i) ensuring at least $50 \%$ of eligible people receive drug therapy to prevent heart attack and stroke and (ii) $80 \%$ availability of the affordable essential medicines, including generics, required to treat major NCDs in both public and private facilities [31]. However, the PURE study revealed that less than $50 \%$ of patients with CVD in high income countries and less than $10 \%$ of patients in low income countries received the three or more proven effective drugs for secondary prevention [32]. The reasons for this poor rates of therapy was both non-availability and unaffordability of these medicines in upper middle-income, lower middle-income and low-income countries [33]. The polypill is thus well suited to fill this void and provide alternative cardiovascular preventive therapeutic strategy as the current mode of administering secondary prevention does not seem to be working. The affordability and availability of these medicines could be improved by providing them through a publically financed or subsidised universal health coverage programme. Large scale-pooled public procurement of the drug could help substantially drive down the prices.

\section{Conclusions}

In its journey of the past decade, the polypill has travelled from a hyped concept to attaining acceptability in the competitive world of pharmacotherapeutics. The available studies do seem to favour the polypill in terms of improving adherence and reducing the cardiovascular risk burden of high blood pressure and dyslipidemia. The extent of its impact on major cardiovascular events would become evident in the near future through large trials with outcome endpoints. If positive, this would probably increase its acceptability among physicians and health administrators to unreservedly accept it in their armamentarium to fight the mounting burden of CVD. In the 
meanwhile, strategies to prevent CVD through improved behaviours and judicious use of available drugs must be implemented effectively through an efficient health system. The polypill can fit well in to such a system but cannot substitute for it.

\section{Compliance with Ethics Guidelines}

Conflict of Interest Ambuj Roy, Nitish Naik, and K. Srinath Reddy declare that they have no conflict of interest.

Human and Animal Rights and Informed Consent This article does not contain any studies with human or animal subjects performed by any of the authors.

Open Access This article is distributed under the terms of the Creative Commons Attribution 4.0 International License (http:// creativecommons.org/licenses/by/4.0/), which permits unrestricted use, distribution, and reproduction in any medium, provided you give appropriate credit to the original author(s) and the source, provide a link to the Creative Commons license, and indicate if changes were made.

\section{References}

Papers of particular interest, published recently, have been highlighted as:

- Of importance

•- Of major importance

1. Wald NJ, Law MR. A strategy to reduce cardiovascular disease by more than 80\%. BMJ. 2003 Jun 28;326(7404):1419.

2. Bramlage P, Sims H, Minguet J, Ferrero C. The polypill: an effective approach to increasing adherence and reducing cardiovascular event risk. Eur J Prev Cardiol. 2017;24(3):297-310. This paper provides a comprehensive review of studies on polypill and their impact on adherence. It also summarises ongoing trials of polypill

3. GBD 2015. Mortality and causes of death collaborators. Global, regional, and national life expectancy, all-cause mortality, and cause-specific mortality for 249 causes of death, 1980-2015: a systematic analysis for the global burden of disease study 2015 . Lancet. 2016;388(10053):1459-544.

4. Reddy KS. Cardiovascular disease in non-western countries. N Engl J Med. 2004 Jun 10;350(24):2438-40.

5. Piepoli MF, Hoes AW, Agewall S, Albus C, Brotons C, Catapano AL, et al. 2016 European guidelines on cardiovascular disease prevention in clinical practice: the sixth joint task force of the European Society of Cardiology and Other Societies on cardiovascular disease prevention in clinical practice (constituted by representatives of 10 societies and by invited experts) developed with the special contribution of the European Association for Cardiovascular Prevention \& rehabilitation (EACPR). Eur Heart J. 2016;37(29): 2315-81.

6. Smith SC, Benjamin EJ, Bonow RO, Braun LT, Creager MA, Franklin BA, et al. AHA/ACCF secondary prevention and risk reduction therapy for patients with coronary and other atherosclerotic vascular disease: 2011 update. Circulation. 2011;124(22): $2458-73$.
7. Hippisley-Cox J, Coupland C. Effect of combinations of drugs on all cause mortality in patients with ischaemic heart disease: nested case-control analysis. BMJ. 2005;330(7499):1059-63.

8. Østergaard L, Fosbøl EL, Roe MT. The role of antiplatelet therapy in primary prevention. A review. Curr Pharm Des. 2016 Dec 5. [Epubahead of print] doi:10.2174/1381612822666161205115540

9. Ridker PM, Danielson E, Fonseca FAH, Genest J, Gotto AM, Kastelein JJP, et al. Rosuvastatin to prevent vascular events in men and women with elevated C-reactive protein. N Engl J Med. 2008;359(21):2195-207.

10. Yusuf S, Lonn E, Pais P, Bosch J, López-Jaramillo P, Zhu J, et al. Blood-pressure and cholesterol lowering in persons without cardiovascular disease. N Engl J Med. 2016;374(21):2032-43.

11. Bittencourt MS, Blaha MJ, Blankstein R, Budoff M, Vargas JD, Blumenthal RS, et al. Polypill therapy, subclinical atherosclerosis, and cardiovascular events - implications for the use of preventive pharmacotherapy. J Am Coll Cardiol. 2014;63(5):434-43.

12. Selak V, Elley CR, Bullen C, Crengle S, Wadham A, Rafter N, et al. Effect of fixed dose combination treatment on adherence and risk factor control among patients at high risk of cardiovascular disease: randomised controlled trial in primary care. BMJ. 2014;348:g 3318.

13. PILL Collaborative Group, Rodgers A, Patel A, Berwanger O, Bots $\mathrm{M}$, Grimm R, et al. An international randomised placebo-controlled trial of a four-component combination pill ("polypill") in people with raised cardiovascular risk. PLoS One. 2011;6(5):e19857.

14. Wald DS, Morris JK, Wald NJ. Randomized polypill crossover trial in people aged 50 and over. PLoS One. 2012;7(7):e41297.

15. Indian Polycap Study (TIPS), Yusuf S, Pais P, Afzal R, Xavier D, Teo K, et al. Effects of a polypill (polycap) on risk factors in middleaged individuals without cardiovascular disease (TIPS): a phase II, double-blind, randomised trial. Lancet. 2009;373(9672):1341-51.

16. Yusuf S, Pais P, Sigamani A, Xavier D, Afzal R, Gao P, et al. Comparison of risk factor reduction and tolerability of a full-dose polypill (with potassium) versus low-dose polypill (polycap) in individuals at high risk of cardiovascular diseases: the second Indian polycap study (TIPS-2) investigators. Circ Cardiovasc Qual Outcomes. 2012;5(4):463-71.

17. Lafeber M, Grobbee DE, Schrover IM, Thom S, Webster R, Rodgers A, et al. Comparison of a morning polypill, evening polypill and individual pills on LDL-cholesterol, ambulatory blood pressure and adherence in high-risk patients; a randomized crossover trial. Int J Cardiol. 2015;181:193-9.

18. Thom S, Poulter N, Field J, Patel A, Prabhakaran D, Stanton A, et al. Effects of a fixed-dose combination strategy on adherence and risk factors in patients with or at high risk of CVD: the UMPIRE randomized clinical trial. JAMA. 2013;310(9):918-29.

19. Patel A, Cass A, Peiris D, Usherwood T, Brown A, Jan S, et al. A pragmatic randomized trial of a polypill-based strategy to improve use of indicated preventive treatments in people at high cardiovascular disease risk. Eur J Prev Cardiol. 2015;22(7):920-30.

20.• Webster R, Patel A, Selak V, Billot L, Bots ML, Brown A, et al. Effectiveness of fixed dose combination medication ('polypills') compared with usual care in patients with cardiovascular disease or at high risk: a prospective, individual patient data meta-analysis of 3140 patients in six countries. Int J Cardiol. 2016;205:147-56. This is a recent meta-analysis encompassing data from largest number of patients from clinical trials on polypill

21. Castellano JM, Sanz G, Peñalvo JL, Bansilal S, Fernández-Ortiz A, Alvarez L, et al. A polypill strategy to improve adherence: results from the FOCUS project. J Am Coll Cardiol. 2014;64(20):2071-82.

22. Huffman MD. THe polypill: from promise to pragmatism. PLoS Med. 2015; 12(8):e1001862. A recent review on polypill that suggests steps to improve the acceptability and use of polypill.

23. Stone NJ, Robinson JG, Lichtenstein AH, Bairey Merz CN, Blum CB, Eckel RH, et al. 2013 ACC/AHA guideline on the treatment of 
blood cholesterol to reduce atherosclerotic cardiovascular risk in adults: a report of the American College of Cardiology/American Heart Association task force on practice guidelines. Circulation. 2014;129(25 Suppl 2):S1-45.

24. Blood pressure-lowering treatment based on cardiovascular risk: a meta-analysis of individual patient data. Lancet. 2014;384(9943): $591-8$.

25. Lonn EM, Bosch J, López-Jaramillo P, Zhu J, Liu L, Pais P, et al. Blood-pressure lowering in intermediate-risk persons without cardiovascular disease. N Engl J Med. 2016;374(21):2009-20.

26. de Cates AN, Farr MRB, Wright N, Jarvis MC, Rees K, Ebrahim S, et al. Fixed-dose combination therapy for the prevention of cardiovascular disease. Cochrane Database Syst Rev. 2014;4:CD009868.

27. The International Polycap Study 3 (TIPS-3) - Full Text ViewClinical Trials.gov [Internet]. 2017 [cited 2017 Jan 19]. Available from: https://clinicaltrials.gov/ct2/show/NCT01646437

28. Secondary Prevention of Cardiovascular Disease in the Elderly Trial-Full Text View-ClinicalTrials.gov [Internet]. [cited 2017 Jan 18]. Available from: https://clinicaltrials.gov/ct2/show/ NCT02596126?term $=$ NCT02596126\&rank $=1$
29. Ostovaneh MR, Poustchi H, Hemming K, Marjani H, Pourshams A, Nateghi A, et al. Polypill for the prevention of cardiovascular disease (PolyIran): study design and rationale for a pragmatic cluster randomized controlled trial. Eur J Prev Cardiol. 2015;22(12):1609-17.

30. Kernan WN, Ovbiagele B, Black HR, Bravata DM, Chimowitz MI, Ezekowitz MD, et al. Guidelines for the prevention of stroke in patients with stroke and transient ischemic attack. Stroke. 2014; Stroke. 2014;45(7):2160-236.

31. WHO | About 9 voluntary global targets [Internet]. WHO. [cited 2017 Jan 19]. Available from: http://www.who.int/nmh/ncd-tools/ definition-targets/en/

32. Yusuf S, Islam S, Chow CK, Rangarajan S, Dagenais G, Diaz R, et al. Use of secondary prevention drugs for cardiovascular disease in the community in high-income, middle-income, and low-income countries (the PURE study): a prospective epidemiological survey. Lancet. 2011;378(9798):1231-43.

33. Khatib R, McKee M, Shannon H, Chow C, Rangarajan S, Teo K, et al. Availability and affordability of cardiovascular disease medicines and their effect on use in high-income, middle-income, and low-income countries: an analysis of the PURE study data. Lancet. 2016;387(10013):61-9. 